\title{
PERANCANGAN SIGN SYSTEM TAMAN WISATA HAIROS INDAH
}

\author{
Suprianingsih \\ Universitas Potensi Utama \\ Suprianingsih97@gmail.com
}

\begin{abstract}
ABSTRAK
Sign System ialah suatu symbol yang bertujuan sebagai media dalam melakukan interaksi manusia dalam ruang public. Sign System dirancang sebagai media yang mampu mengarahkan oaring-orang agar dapat lebih muda menemukan suatu tempa dalam lingkungan sebuah gedung, taman wisata serta ruang public lainnya. Hal ini sangat membatu bagi orang-orang yang baru pertama kali mengunjugi tempat tersebut, pada umumnya Sign System ini dibuat di tempat yang sangat luas. Dengan adanya Sign System orang yang belum mengenal lokasi yang dikunjugi dapat dengan mudah menuju lokasi yang diinginkan tampa takut tersesat dan banyak bertanya kepada orang-orang disekitar lokasi yang dikunjugi.
\end{abstract}

Kata Kunci : Sign System, Symbol, Ruang Buplik

\section{ABSTRACT}

The Sign System is a symbol that serves as a medium for human interaction in the public space. The Sign System is designed as a medium that is able to direct people to be younger in finding a place in the environment of a building, tourist park and other public spaces. This is very helpful for people who are visiting this place for the first time, in general, this Sign System is made in a very large area. With the Sign System, people who don't know the location they are visiting can easily go to the desired location without fear of getting lost and asking many people around the visited location.

Keywords : Sign System, Symbol, Buplik Room

\section{PENDAHULUAN}

Sign System ialah suatu symbol yang bertujuan sebagai media dalam melakukan interaksi manusia dalam ruang public. Dalam pengertian lainnya, Sign System Juga sebagai petunjuk bagi mereka yang membutuhkannya. Sign System pun harus mempunyai fungsi yang jelas dan efisien.

Hairos Indah Medan adalah wisata rekreasi keluarga yang berlokasi di Jln Jamin Ginting Km.14 Medan tempat wisata ini sangatlah cocok untuk kita kunjungi pada saatsaat liburan, apalagi jika waktu liburan yang kita miliki sekedar waktu liburan yang singkat, karena tempatnya tidak jauh dari pusat Kota Medan. Pengunjung juga dapat menikmati berbagai fasilitas hiburan yang ada disini, sejak mulai memasuki gerbang pengunjung akan melihat berbagai macam wadah permainan seperti bom bom car, happy 
dragon, mini flight, kuda pusing, video game yang dilengkapi dengan café untuk bersantai. Ada juga kebun binatang, perahu sampan, motor ATV, kincir angin, dan water park sebagai fasilitas hiburan terbaru. (https://travelspromo.com/htm-wisata/hairos-waterparkmedan: 2020)

Di dalam Water Park ini pengunjung juga bisa menikmati beberapa fasilitas hiburan air seperti :

1. Kiddy Pool (kolam anak), Pesta air untuk anak-anak dengan ember tumpah dan slide/seluncuran dengan bentuk beragam.

2. Kolam Ombak, Pertama di Sumatera Utara dengan tehnologi yang khusus di datangkan dari German, dengan luas kolam $1500 \mathrm{~m} /$ segi dan tinggi ombak sekitar $1 / 2 \mathrm{~s} / \mathrm{d} 1$ Meter.

3. Arus, Kolam terpanjang $( \pm 450 \mathrm{M})$ ini memang didesain mengelilingi seluruh wahana yang ada, menikmati arus dengan ban/tube dengan cara tiduran maupun ramai-ramai sudah cukup untuk mengelilingi semua wahana di Hairos Waterpark.

4. Tempat beristirahat dan bersantai sembari mengawasi kesibukan putra-putri anda menikmati wahan yang ada di dalamnya dan.

5. Waterboom setinggi 30 meter dengan tiga jalur yang merupakan tertinggi di Kota Medan dan Sumatera Utara.

Dengan segala pasilitas yang dimiliki oleh Hairos Indah sangan penting untuk membuat Sign System mengingat di Hairos Waterpak belum memiliki pasilitas Sign System. Yang membuat pengunjung tidak mengetahui lokasi-lokasi pasilitas lain dari Hairos Waterpak.Sing System yang akan dibuat ini tidak hanya berbentuk papan penunjuk arah dan peta hairos saja yang akan di letakan di tempat-tempat yang dirasa perlu.

\section{A. Rumusan Penciptaan}

Berdasarkan latar belakang yang telah diutarakan di atas, maka dapat disusun rumusan penciptaan yaitu bagaimana Sign System Hairos Waterpak dapat diaplikasikan di lokasilokasi yang dianggap strategis untuk penempatan serta bagaimana Sign System Hairos Waterpak dapat diaplikasikan dalam bentuk aplikasi digital.

\section{B. Tujuan Penciptaan}

Sesuai dengan rumusan masalah di atas, maka tujuan dari penciptaan karya ini adalah untuk mempermudah pengunjung menemukan lokasi wisata yang dituju.

\section{Manfaat Penciptaan}

Adapun manfaat dari penciptaan karya ini adalah sebagai berikut:

\section{Manfaat Keilmuan}

Penciptaan karya ini diharapkan untuk dapat menjadi petunjuk arah yang baik dan dapat dijadikan panduan bagi pengunjung untuk menemukan lokasi wisata yang diinginkan.

\section{Manfaat Praktis}

Bagi kemajuan jaman aplikasi yang akan dibuat akan menjadi media penunjuk arah yang praktis dan mudah di gunakan. 


\section{KAJIAN TEORI}

Susanne K. Langer merupakan salah satu wanita yang mendalami filsafat sebagai bidangnya. Pemikirannya dipengaruh oleh Ernst Cassirer dan Alfred North Whitehead. Langer terkenal atas karyanya "Philosophy in a New Key" yang berbicara tentang bagaimana simbol mempengaruhi pemikiran manusia menjadi kebutuhan untuk mengekspresikan diri.

Pengertian Simbol yang dimaksud Susanne bukanlah symbol- symbol dalam seni seperti Ikonographik. Jadi bukan symbol yang berdasarkan konvensi atau menjadi referensi, tetapi yang memberikan pendalaman dan bahkan mengarahkan konvensi. Dalam defenisi menurut Susanne, Simbol ialah setiap sarana dimana kita bisa membuat abstraksi. Abstraksi sendiri ialah pelepasan bentuk dari isinya, yaitu pelepasan bentuk yang sama dari isi yang berbeda sehingga terbentuk konsep.

Berdasarkan teori yang ada tentang symbol, symbol dibagi menjadi dua:

1. Simbol diskursif, ialah bentuk yang digunakan secara literal dimana unit- unitnya bermakna berdasarkan konvensi (aturan yg disepakati bersama). Selain itu setiap unit memiliki maknanya sendiri sendiri seperti kata di dalam serangkaian kalimat.

2. Simbol Presentasional, tidak terdiri dari unit- unit yang memiliki arti tetap untuk digabung berdasarkan aturan tertentu dan juga tidak dapat diuraikan. Maknanya ada dalam bentuk totalnya. Contohnya ialah sebuah lukisan yang hanya dapat ditangkap melalui arti secara keseluruhan.

Secara khusus, Susanne Langer memang membuat teori dasar mengenai symbol untuk teori symbol presentasional, dari sana ia mendefenisikan seni sebagai "kreasi bentuk bentuk simbolis perasaan manusia". Defenisi seni ini mengimplikasikan beberapa hal:

a. Seni merupakan kreasi. Kreasi berarti pengadaan sesuatu yang tadinya tidak ada.

b. Rumusan bentuk simbolis. Bentuk simbolis tidak mengacu pada pengalaman sendiri secara langsung melainkan pengalaman yang sudah disimbolkan.

c. Bentuk simbolis yang dilemparkan seniman dalam kreasi seninya tidak berasal dari pikiran melainkan dari perasaannya. Yakni formasi dari pengalaman emosionalnya.

\section{Warna}

Warna merupakan sebuah penomena alam yang dapat dikembangkan lebih jauh dan mendalam. Warna bukanlah sekedar unsur visual yang bisa digunakan oleh senimanseniman lukis sejak jaman purba hingga saat ini. Melalui penemuan tersebut dampaknya sangat luas hingga melampaui bidang disiplin ilmu lainnya. Pigmen sebagai warna buatan atau imitasi dari warna yang tersebar dialam luasini.terdapat dua unsur penting untuk menikmati warna adalah cahaya dan mata. Tanpa kedua unsur tersebut kita tidak akan dapat menikmati warna secara sempurna, karna cahaya adalah sumber warna dan mata adalah media untuk menangkap warna dari sumbernya.

Pigmen merupakan pewarna yang bisa dilarut dalam cairan pelarut, bahan pelarut dapat berupa air atau minyak. Pengelolaan pigmen memerlukan proses yang tepat dan bahan yang baik untuk memberikan hasil yang terbaik. Kualitas pigmen yang baik akan membantu meningkatkan serta memperbaiki muti studi tentang warna penggunanya. 
Sensai pada warna akan terjadi jika ada cahaya, jika tidak terdapat cahaya maka sensai warna tidak akan timbul, hal ini depengaruhi oleh penampilan warna yang masih sangat tergantung pada cahaya.

\section{Rancangan Konsep Garap}

Perancangan karya Sign System Hairos Waterpak ini kana membuat penunjuk arah dilokasi wisata Hairos Waterpak yang berlokasi di kota Medan. Sign System yang dirancang nantinnya akan menunjukan arah dimana lokasi Waterpak, kebun binatang, danau buatan,permainan kuda pusing, bom-bom cart dan tempat naik kereta api serta tempat menaiki delman. Perancangan ini nantinya diharapkan dapat memudahkan pengunjung untuk mengetahui lokasi-lokasi wisata yang akan dituju tanpa kesulitan.

Perancangan tersebut melalui beberapa tahapan design process and planning yaitu:

1. Perencanaan

Tahap ini adalah tahap pengumpulan data yang dibutuhkan mengenai lokasi wisata Hairos Waterpak yang dalam hal ini adalah lokasi-lokasi wisata yang ada didalam hairos Waterpak, serta melihata lokasi-lokasi mana saja yang akan dijadikan tempat peletakan dari Sign System yang akan diarancang.

2. Implementasi

Tahap ini adalah tahap dimana Sing System yang dirancang akan diletakan. Serta pembuatan aplikasi yang akan mempermudah pengunjung mengetahui lokasi-lokasi wisata yang ada dalam arie Hairos Waterpak.

3. Sosialisasi

Tahap sosialisasi adalah tahapan dimana karya dipertunjukkan ke target audience. Penyebaran atau sosialisasi karya ini dilakukan melalui media sosial dan Youtube. Sosialisasi juga dilakukan disosial media.

\section{Kesatuan/Unity}

Menurut Sadjiman Ebdi Sanyoto(2009), kesatuan (Unity) merupakan salah satu prinsip dasar tata rupa. Unity bias juga disebut keutuhan. Seluruh bagian-bagian atau dari semua unsur/elemen yang disusun harus saling mendukung, tidak ada bagian-bagian yang mengganggu, Sing System yang dibuat dan disesuaikan agar semua elemen yang ada mengesankan satu kesatuan.

\section{Dominasi}

Menurut Sadjiman Ebdi Sanyoto(2009), Dominasi dalam karya seni bias disebut penjajah atau yang menguasai. Namun, dominasi bisa juga disebut keunggulan, keistimewaan, keunikan, keganjilan, kelainan/penyimpangan (anomali). Setiap karya seni harus memiliki dominasi agar menarik karena unggul, istimewa, unik, ganjil, maka akan menjadi menarik dan pusat perhatian, menjadi klimaks. Jadi, dominasi bertugas sebagai pusat perhatian dan daya tarik. Dalam hal ini, yang menjadi titik dominasi adalah karagaman wisata yang ada dalam Hairos Waterpak.

\section{Keseimbangan}

Menurut Sadjiman Ebdi Sanyoto(2009), Keseimbangan merupakan salah satu prinsip dasar seni rupa. Karya seni/desain harus memiliki keseimbangan agar enak dilihat, tenang, tidak berat sebelah, tidak menggelisahkan, tidak menggelimpang. Keseimbangan dalam karya seni/desain dapat pula diartikan sebagai suatu keadaan ketika di semua bagian pada karya tidak ada yang lebih terbebani. Jadi, karya bebannya sama, sehingga pada gilirannya akan membawa rasa tenang dan enak dilihat. Ada beberapa jenis keseimbangan, antara lain adalah sebagai berikut: 
a. Keseimbangan Simetris

Keseimbangan simetris yaitu keseimbangan antara ruang sebelah kiri dan ruang sebelah kanan sama persis, baik dalam bentuk rautnya, besarnya ukurannya, arahnya, warnanya, maupun teksturnya.

b. Keseimbangan memancar

Keseimbangan memancar sesungguhnya sama dengan keseimbangan simetri, tetapi kesamaan polanya bukan hanya di antara ruang sebelah kiri dan ruang sebelah kanan saja, melainkan juga antara ruang sebelah atas dan ruang sebelah bawah.

c. Keseimbangan sederajat

Keseimbangan sederajat yaitu keseimbangan komposisi antara ruang sebelah kiri dan ruang sebelah kanan tanpa mempedulikan bentuk yang ada di masing-masing ruang. Jadi, meskipun memiliki bentuk raut yang berbeda, tetapi besarnya sederajat, misalnya bentuk raut lingkaran dengan bentuk raut segitiga dengan besaran yang sama.

d. Keseimbangan tersembunyi (Asimetris)

Keseimbangan tersembunyi sering kali disebut juga keseimbangan asimetris, yaitu keseimbangan antara ruang sebelah kiri dan ruang sebelah kanan meskipun keduanya tidak memiliki besaran sama maupun bentuk raut sama. (Sadjiman Ebdi Sanyoto(2009).

Layout yang digunakan pada karya ini menerapkan prinsip keseimbangan yang ada agar penempatan objek-objek didalamnya tetap terkesan dinamis dan tidak brantakan. Pengaturan tata letak konten agar target audience mudah menangkap pesan yang disampaikan. Keseimbangan tidak hanya memperhatikan ruang yang berisi konten tetapi juga memperhatikan ruang kosong.

\section{Proporsi}

Menurut Sadjiman Ebdi Sanyoto(2009), Proporsi berasal dari kata inggris proportion yang artinya perbandingan, proporsional. Dengan demikian, proporsi dapat diartikan perbandingan atau kesebandingan yakni dalam suatu objek antara bagian satu dengan bagian lainnya sebanding.Proporsi antara Hairos waterpak dengan objek pendukung seperti wisata-wisata yang ada didalam Hairos Waterpak disesuaikan agar objek utama tidak tekesan tenggelam sehingga fokus penonton dapat tetap diarahkan ke objek utama tanpa mengurangi nilai dari keh adiran objek pendukung.

\section{Kesederhanaan}

Menurut Sadjiman Ebdi Sanyoto(2009), Kesederhanaan dalam setiap karya seni maupun desain adalah tidak lebih dan tidak kurang, jika ditambah terasa menjadi ruwet dan jika dikurangi terasa ada yang hilang. Sederhana bukan berarti harus sedikit, tetapi yang tepat adalah "pas", artinya tidak lebih dan tidak kurang. Prinsip ini diterapkan agar fokus penonton tidak kabur karena terlalu banyak objek yang mencolok atau yang muncul di dalam satu layar. Terlalu banyak objek akan menyulitkan dalam memahami apa yang sedang diterangkan pada suatu bagian.

\section{Arsitektur}

Menurut Lynch (1962), kualitas fisik yang diberikan oleh sistem visual pada suatu tempat dapat menimbulkan image yang kuat terhadap tempat tersebut. Kualitas yang berupa kemampuan mendatangkan kesan (imageability) dimana berkait erat dengan kejelasan atau kemampuan untuk dibaca (legibility) pada suatu tempat.Image suatu tempat berkaitan dengan tiga komponen, yaitu: 


\section{Identitas}

Obyek dapat membedakan dengan obyek lainnya.

2.Struktur

Mencakup pola hubungan antara obyek dengan pengamat, serta obyek satu dengan obyek lainnya dalam suatu tempat.

3.Makna

Obyek dapat mengalami ruang perkotaan yaitu dari obyek-obyek, arti subyek-obyek dan rasa yang dialami.

Komponen pembentuk karakter dari aspek non fisik diambil dari kriteria desain tak terukur menurut Urban System Research and Engineering Inc, dimana lebih menekankan pada kualitas visual, yaitu:

1. Kelayakan hubungan (fit with setting) Menitik beratkan pada harmoni kota yang berkaitan dengan lokasi, kepadatan perumahan, budaya, nilai bangunan, artefak jalan.

2. Ekspresi dan Identitas (Expressioan of Identity) Memberikan ekspresi identitas, status dan nilai-nilai bagi penghuni dan masyarakat dalam penekanan desain.

3. Pencapaian dan Orientasi (Access and Orientation) Kejelasan dan keamanan pintu masuk, jalan kearah lokasi penting sehingga orang mengertiakan kemana.

4. Pendukung aktifitas (Activity support) Kegiatan masyarakat akan memberikan karakter perilaku melalui tanda-tanda yang didesain khusus.

5. Pemandangan (view) Menekankan pada pencapaian dari bangunan ke arah ruang publik.

6. elemen alam (Natural Elemen) Menciptakan desain dengan memanfaatkan unsur alam yang ada pada lokasi.

7. Tampak yang Nyaman (Visual comfort) Menghindari adanya gangguan silau, asap, debu ataupun traffic light yang membingungkan.

8. Kepedulian dan Perawatan (Care and Maintenance) Memperhatikan pemilihan komponen dalam desain yang mudah perawatan dan pengelolaannya. (Darmawan, 2003).

\section{STUDI LITERATUR}

Kajian sumber penciptaan adalah melihat (mereview) karya seni sebelumnya yang berkaitan dengan fokus karya yang digarap. Kajian sumber perancangan dilakukan guna menghindari kesanmaan karya yang diciptakan sudah pernah dirancang sebelumnya, agar orisinalitas karya seni terbukti.

Salah satu karya yang menjadi rujukan dalam penyelesaian karya ini adalah konsep visual sistem sarana isyarat penunjuk (Sign System) di kampus syahdan binus university. 


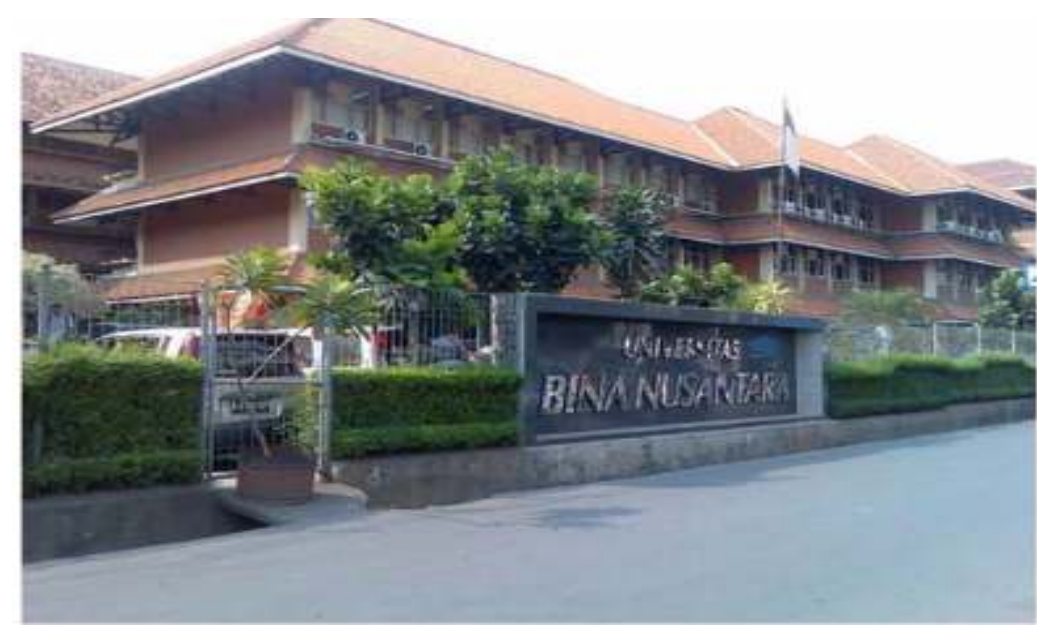

Gambar 1: kampus Syahdan BINUS University

Sumber :binus.ac.id/uploads/paper/document/publication/Proceeding/Humaniora

Konsep visual sistem sarana isyarat penunjuk (Sign System) di kampus syahdan binus university. Sing system yang dibuat pada kampus Syahdan BINUS dikarnakan aktivitas kampus yang padat sehingga di rasa perlu untuk membuat petunjuk arah di area kampus Syahdan BINUS. Hal lain yang dihawatirkan adalah masalah dana yang akan dikeluarkan untuk membuat Sing System di area kampus Syahdan BINUS tidaklah sedikit.

Kemudian Perancangan Desain Sign System Pasar Rasamala Semarang perancangan Sing System ini di buat untuk menunjukan tempat-tempat penjuan bahan pangan dari mulai tempat penjual sayuaran, ikan, jajanan psara, daging sembako, bumbu dapur dan segala sesuatu yang terdapat di Pasar Rasamala Semarang.
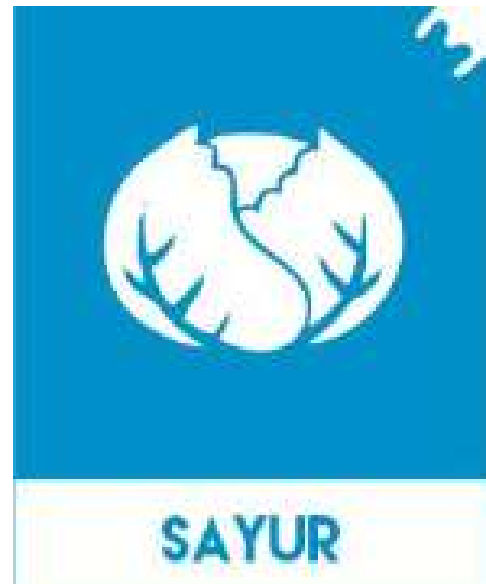

Gambar 2. Sing System sayuran

(Sumber: http://eprints.dinus.ac.id/15286/1/jurnal_15313.pdf)

\section{Visualisasi Karya}

a. Sing System Hairos Indah 
b. Mini Zoo

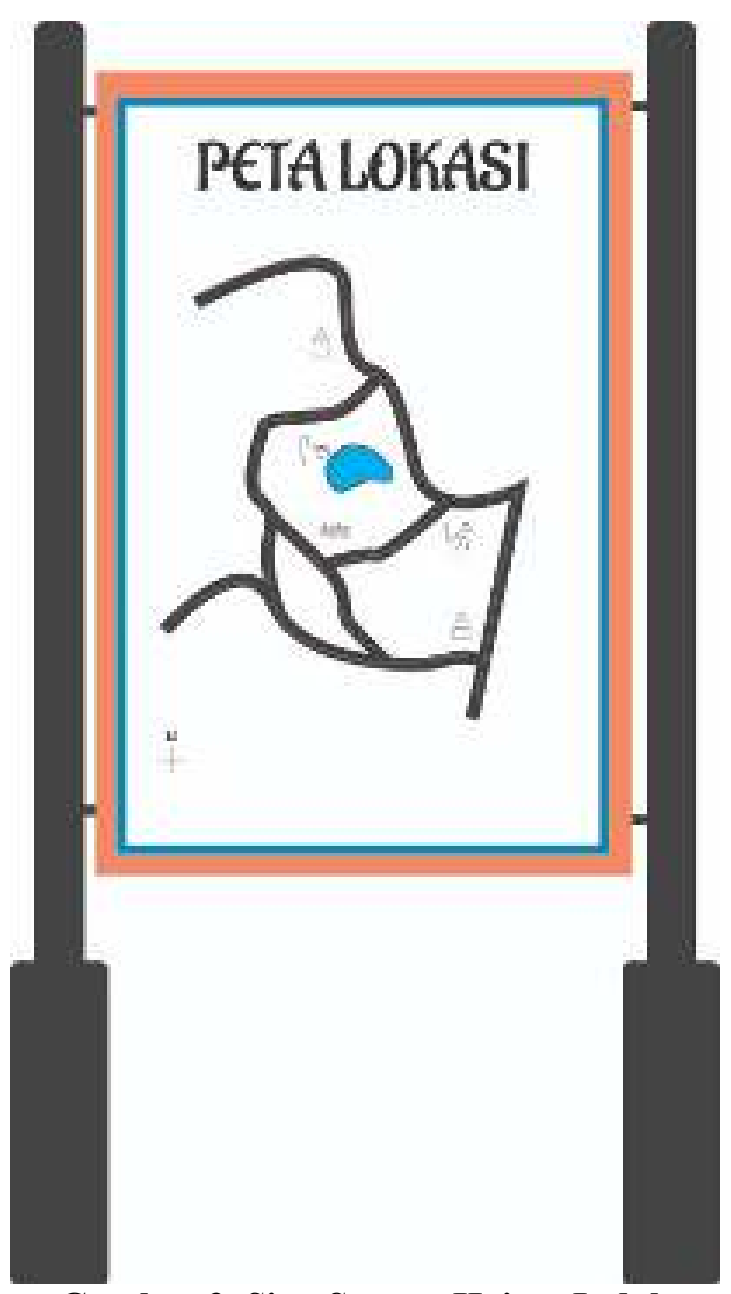

Gambar 3. Sign System Hairos Indah

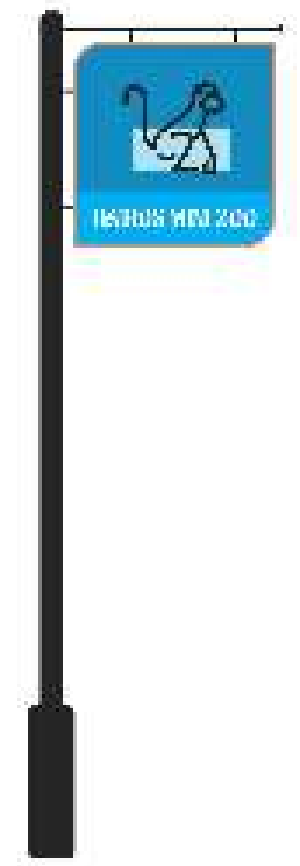

Gambar 4. Mini Zoo 
c. Water Slider

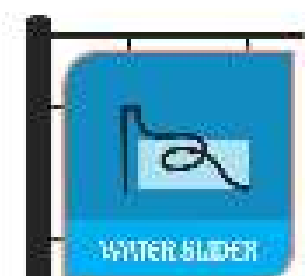

Gambar 5. Water Slider

d. Kolam Arus

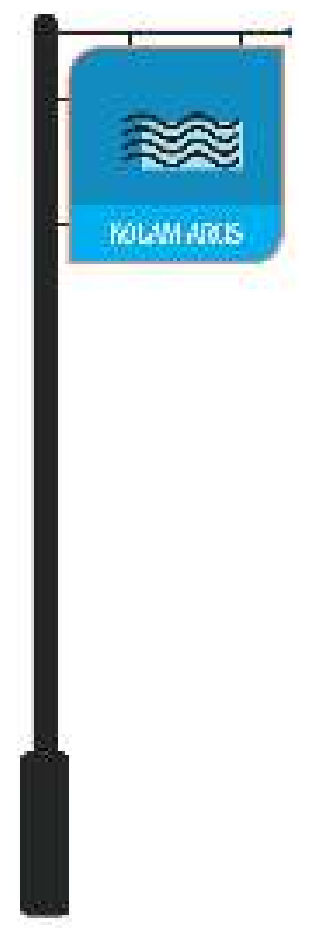

Gambar 6. Kolam Arus 
e. Kolam Air Terjun

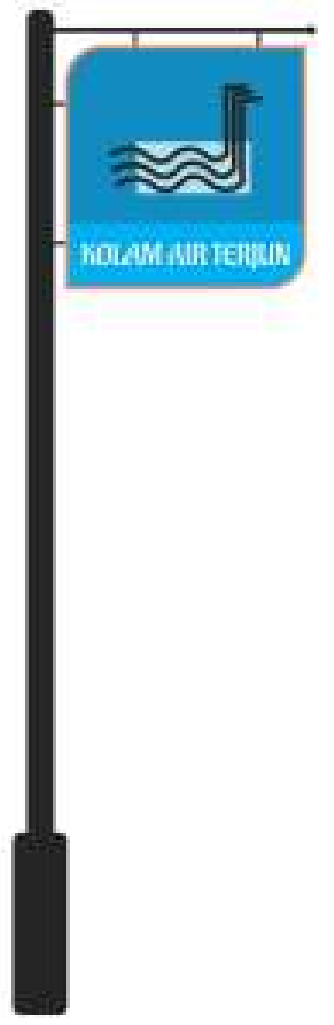

Gambar 7. Kolam Air Terjun

f. Kolam Air Menari

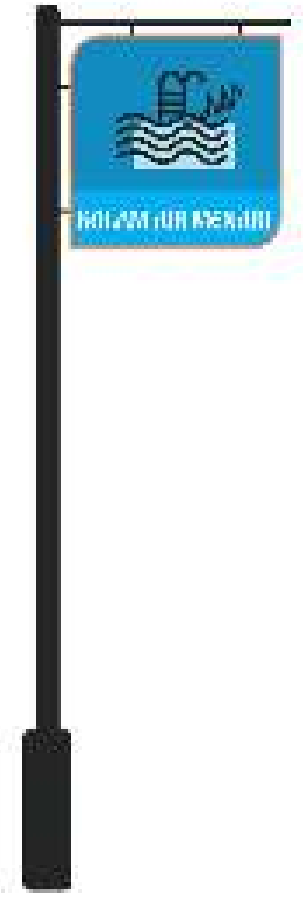

Gambar 8 Kolam Air Menari 
g. Kolam Anak



Gambar 9. Kolam Anak

h. Kolam Ombak

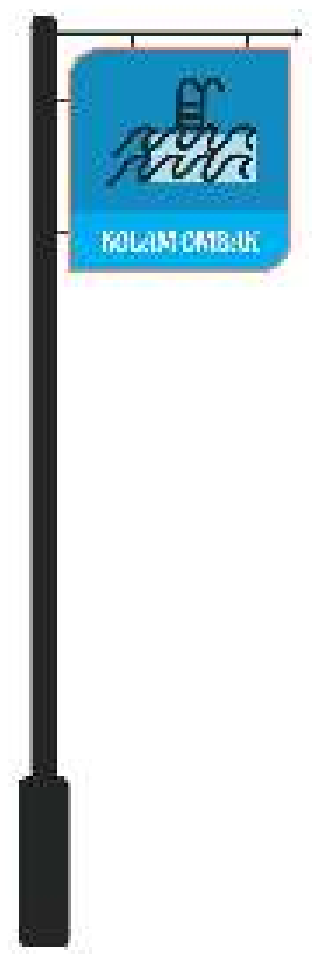

Gambar 10. Kolam Ombak 


\section{KESIMPULAN}

Sign System amat penting dibuat pada sebuah taman wisata maupun tempat-tempat umum lainnya, hal ini dikarna fungsi utama dari sign System yaitu sebagai petunjuk arah agar seseorang dapat dengan mudah menemukan sebuah lokasi yang ingin di tuju pada tempat-tempat wisata maupun pasilitas umum lainnya.

Wisata air hairos indah membutuhkan sign system dikarnakan luasnya wisata tersebut, pemasangan sign system dilokasi-lokasi yang tepat dapat sangat membantu para pengunjung untuk menghemat waktu pada saat berwisata, selain menghemat waktu sign system juga dapat mengantarkan para wisatawan ketempat-tempat wahana yang diinginkan dengan mudah.

Warna merupaka sepektrum alam yang dapat mewakili sebuah kepribadian seseorang, pigmen warna akan muncul secara maksimal dengan bantuan cahaya yang baik, tanpa pencahayaan yang baik maka warna yang terlihat atau keluar dari sebuah karya seni tidak akan maksimal.

\section{DAFTAR PUSTAKA}

[1] Ahada Nakatama, Mhicyko. 2017. Perancangan Sign System Objek Wisata Lembah Harau Kabupaten Lima Puluh Kota. Padang: Sarjana UNP

[2] Ratna, N.K., (2010). Metodologi Penelitian: Kajian Budaya dan Ilmu-ilmu Sosial Humaniora Pada Umumnya. Yogyakarta: Pustaka Pelajar.

[3] Suryajaya, Martin (2016). Sejarah Estetika. Jakarta: gang Kabel.

[4] Calori, Chris. (2007). Signage and Wayfinding Design. New Jersey, Jon Wiley and Sons, Inc.

[5] Suryandi. (2013) Filsafat Seni. Yogyakarta: Lintang Pustaka Utama.

[6] Sumardjo, Jakoba (2000) Filsafat Seni. Bandung: ITB

[7] Lankow, Ritchie, Crooks. (2014). Infografis: Kedahsyatan Cara Bercerita Visual Jakarta: PT. Gramedia Pustaka Utama

[8] Ching, D.K Francis. 1996, Ilustrasi DesainInterior. Jakarta: Erlangga.

[9] Ardina, Yanti Mila. 2015. Estetika Dalam Arsitektur, PT.WIDIA INOVASI NUSANTARA, Jakarta Barat

[10] Pratikno, priyo, 2011, Etika Dan Estetika, C.V ANDI OFFSET, Yogyakarta.

[11] Darmaprawira, Sulasmi, 2002, Warna Teori dan Kreativitas Pnggunaan Warna, ITB, Bandung 
[12] Eaton, Muelder Marcia, 2010, Persoalan-Persoalan Dasar Estetika, Salemba Humanika, Jakarta

[13] Kurniawan, Harry, 2015, Arsitektur Minimalis Memahami Minimalis Dalam Arsitektur, Universitas Gajah Mada (UGM), Yogyakarta.

[14] Majidah, dkk. (2019). Penggunaan Warna Dalam Disain Interior Perpustakaan Terhadap 